\title{
Georges Cuvier: história natural em tempos pré-darwinianos
}

\author{
Georges Cuvier: natural history in pre-Darwinian times
}

\author{
F. Felipe A. Faria \\ Doutor em ciências humanas pela Universidade Federal de Santa Catarina \\ felipeafaria@uol.com.br
}

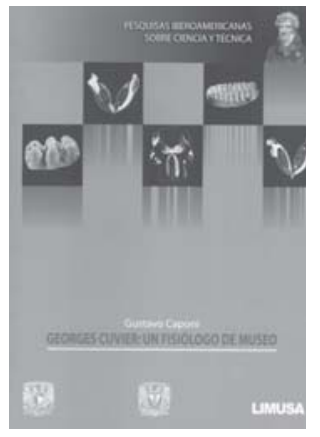

CAPONI, Gustavo. Georges Cuvier: un fisiólogo de museo. México: Unam; Limusa. 2008. $157 \mathrm{p}$.
G eorges Cuvier (1769-1832) é um dos nomes mais importantes da história do pensamento biológico. Durante a primeira metade do século XIX, seus trabalhos e ideias foram referência obrigatória em todas as áreas da história natural. Sua teoria catastrofista, a comprovação do fenômeno da extinção e suas reconstruções paleontológicas, além de permitir, em sua época, melhor compreensão da história natural dos seres 'desaparecidos' (extintos) e viventes, preparou terreno para uma revolução epistemológica, a revolução darwiniana, que se instalaria em todas as áreas das ciências biológicas.

Ao empreender seu programa de pesquisa, Cuvier realizou contribuições fundamentais em três áreas-chave da história natural: a anatomia comparada, a taxonomia e a paleontologia. De acordo com tal programa, essas três áreas se integravam e complementavam em único objetivo cognitivo: compreender a organização dos seres vivos e extintos recorrendo a um método de classificação natural. Segundo Cuvier, esse método deveria estar fundamentado na análise das diferentes formas com que esses seres integravam e coordenavam suas diferentes funções.

Ao utilizar tal critério, ele integrava os dois polos da oposição ainda existente na época, entre os conceitos de história natural e filosofia natural. De acordo com essa polaridade, a filosofia natural tratava das relações causais e matemáticas entre os fenômenos naturais, e a história natural voltava-se para a descrição e classificação desses fenômenos e dos objetos naturais de todos os tipos. Porém, como sinaliza Gustavo Caponi em seu livro Georges Cuvier: un fisiólogo de museo, não há, em nenhum desses polos, um sentido histórico. No programa cuvieriano a história natural tem o sentido de física particular, que remete a uma ciência teórica, voltada para o estabelecimento das leis da organização dos seres vivos, e não para uma ciência que preserva o seu lastro histórico, tal como a entendemos hoje.

Esse tipo de esclarecimento, feito por Caponi, é de suma importância para entender o cenário intelectual e científico dos anos que antecederam o advento do evolucionismo, desencadeado pela revolução darwiniana. Sua análise destaca a necessidade desse 
entendimento para melhor compreensão da forma com que Darwin estabeleceu sua argumentação e a defesa de suas ideias e, consequentemente, como o cientista promoveu sua revolução epistemológica. Sendo a anatomia comparada de Cuvier a mais elaborada expressão do pensamento pré-darwiniano no domínio das ciências da vida e da terra, era contra esse tipo de pensamento estabelecido que Darwin direcionaria seus argumentos. Os dados que a anatomia comparada de Cuvier produzia se voltavam para uma história natural que, por não levar em conta as alterações dos organismos ao longo do tempo, se distanciava de um pensamento evolutivo. Apesar dessa prescindência, tais dados tornarse-iam fundamentais para o estudo da genealogia dos seres vivos, principalmente por dotar de argumentos sólidos e convincentes a ideia de comunidade de descendência, permitindo reconstruções paleontológicas e, por conseguinte, filogenéticas.

Esse fator, paradoxalmente, teria colocado Georges Cuvier na linhagem histórica do que, muito tempo depois, Ernst Mayr e François Jacob chamariam de biologia evolutiva. O paradoxo se torna óbvio quando lembramos da posição antitransformista mantida por Cuvier nos debates que travou com Lamarck, cujas ideias atacou utilizando dados empíricos, em vez de evocar as leis da anatomia comparada, como a inexistência de diferenças anatômicas entre animais atuais e animais mumificados da antiguidade egípcia, ou, ainda, a ausência de formas intermediárias no registro fossilífero. Cuvier só utilizaria uma argumentação 'fisiológica' contra as ideias de Lamarck em seu ataque à versão biológica da 'cadeia dos seres' que este último defendia.

Esse tipo de argumentação, centrada na organização interna dos seres vivos, seria intensamente utilizada por Cuvier durante toda a sua carreira, em particular numa série de debates que ficou conhecida como Polêmica dos Análogos. Os debates ocorreram entre ele e seu colega de instituição de pesquisa, Geoffroy Saint-Hilaire, que propunha uma teoria de 'unidade de composição', baseada na ideia da existência de um plano único de organização dos seres vivos.

Nesse ponto, o livro de Gustavo Caponi representa uma contribuição valiosa para esclarecer algumas questões envolvidas nessa polêmica. Ao contrapor aspectos centrais dos programas de pesquisa de cada um dos envolvidos, o autor destaca a divergência de Cuvier e Geoffroy quanto ao sentido do termo organização, que para o primeiro seria funcional, portanto relacionado à fisiologia, e para Geoffroy seria constitucional, ou seja, vinculado à ontogenia dos seres.

A condição fundamental para entender a posição de Cuvier na linha sucessória da biologia que Mayr e Jacob chamaram de funcional, à qual a fisiologia atualmente se vincula, é considerar que todo seu trabalho foi orientado pela aplicação desse sentido funcional para a compreensão da organização dos seres vivos. Essa é uma das propostas centrais do livro de Caponi, tão adequadamente intitulado.

$\mathrm{Na}$ apresentação, o autor expõe a distinção entre o campo da biologia encarregado das 'causas próximas', a 'biologia funcional', e aquele que se encarrega das 'causas remotas', a 'biologia evolutiva'. Até os tempos de Darwin essa distinção não se fazia presente, pois os objetivos cognitivos evolucionistas só se consolidariam após a aceitação de sua teoria. Como vimos, após tal consolidação Cuvier passou a ser frequentemente posicionado na linha sucessória da biologia evolutiva, sendo pouco reconhecido seu papel no delineamento 
da sucessão entre sua fisiologia e a biologia funcional da atualidade. Um dos fatores que explicam essa situação, segundo Caponi, é a inexistência de experimentalismo na fisiologia cuvieriana, atualmente o método hegemônico de produção de conhecimento na área da biologia funcional.

Por ser impossível, na época, apresentar comprovações obtidas pelo método experimental no campo fisiológico, Cuvier utilizava a observação e a comparação para o estabelecimento das leis de funcionamento dos corpos organizados. Para produzir uma ciência centrada nos processos aí envolvidos, ele formularia leis da anatomia comparada até hoje utilizadas. Essa universalidade temporal das leis de Cuvier, além do fato de grande parte de sua metodologia anatomocomparativa ter se mantido até os dias atuais, deveria fazer com que o cientista fosse incluído na linhagem histórica da sucessão de ideias e métodos que compõem a atual biologia funcional. Suas leis baseiam-se em princípios que definem a organização e limitam as possibilidades de alteração das partes de um organismo. Um deles, o princípio das condições de existência, como aponta Gustavo Caponi, é o axioma sobre o qual se centrava todo o programa cuvieriano de investigação. O princípio rezava que as partes de um organismo deveriam estar coordenadas de tal forma que possibilitassem sua totalidade funcional, não só em relação a si mesmo, mas também em relação ao entorno.

Tal relação com o entorno, se analisada de modo descontextualizado, pode levar a uma interpretação ecológica do princípio. Darwin e Wallace assim o fizeram quando utilizaram a expressão 'condições de existência' no sentido de 'condições de vida', ou seja, as condições ambientais relacionadas às contingências da luta pela sobrevivência. Mas não era essa a intenção de Cuvier ao formular tal princípio. Para ele o entorno estava relacionado ao ambiente físico em que o ser estava inserido e que poderia influenciar em sua organização através da troca de matéria ou mesmo da influência de propriedades físicas, como por exemplo o ar e a temperatura. Nesse entorno, as interações entre os seres limitar-se-iam à troca de substâncias, que ocorriam através de predação, herbivoria etc., pouco importando a existência de outras interações ecológicas.

A pouca importância atribuída às interações ecológicas, como analisa Caponi, decorria da escassa preocupação de Cuvier com o meio ambiente. Para ele a inserção no entorno era consequência da organização dos seres e não o inverso, como reconhecido por Darwin. Seria, aliás, a preeminência dos fatores internos sobre os externos aos organismos que proporcionaria a Cuvier realizar reconstruções paleontológicas numa época em que os paleoambientes eram pouco conhecidos. Para realizar essas reconstruções, Cuvier considerava que, por serem universais, as leis que regem a organização dos seres 'desaparecidos' eram as mesmas a reger a organização dos seres atuais. Dessa maneira, ele poderia 'reconstruir' os primeiros e compará-los com os atuais, confirmando a eficácia de suas leis. Na busca por tal confirmação, Cuvier estabeleceu-se como um naturalista de museu, destaca Caponi. O projeto cuvieriano de atingir o conhecimento fisiológico demandava comparações, e elas, por sua vez, exigiam crescente número de espécimes coletados. O local em que estes poderiam ser armazenados, catalogados e expostos era o museu, e o Museu Nacional de História Natural de Paris, onde Cuvier se radicaria, era a instituição de pesquisa na qual se encontrava reunido o maior número dessas peças, permitindo comparações. 
Ser fisiologista de museu, porém, era uma estratégia de trabalho que se esgotaria com a revolução epistemológica que se seguiu na história natural, a revolução darwiniana. Para Darwin, que baseava sua teoria nas relações ecológicas entre os seres vivos, os dados sobre o ambiente em que estes estavam inseridos eram decisivos. Isso implicou uma grande mudança metodológica: da mútua adequação funcional das estruturas orgânicas, para a adequação das mesmas às exigências e oportunidades do ambiente, o que conduziria à considerável alteração do papel do naturalista e, de acordo com Gustavo Caponi, do significado do termo. A nova atribuição dos naturalistas - observar as relações existentes entre os seres vivos - retiraria deles o papel de meros coletores, uma função que, apesar de aparentemente simples, detinha considerável relevância na história natural pré-darwiniana, pois abastecia museus e gabinetes.

Além das observações ecológicas, os naturalistas passariam a considerar fatores históricos capazes de fornecer informações para as reconstruções filogenéticas. A introdução dessa historicidade refletiu-se no novo sentido que a história natural passaria a ter a partir da revolução darwiniana. Deixava ela de ter como função primordial a classificação, ou, como proposto pelo programa de pesquisa cuvieriano, o estabelecimento das leis da organização, e passaria a abranger a parte da biologia que estuda a historicidade da vida, trabalho que seria desenvolvido pelos naturalistas orientados por esse sentido pósdarwiniano da expressão.

Enfim, em Georges Cuvier: un fisiológo de museo, Gustavo Caponi expõe de forma esclarecedora as ideias desse naturalista e a repercussão que tiveram na história natural prédarwiniana. Tal esclarecimento contribui não só para a compreensão do pensamento 'biológico' daquela época, dada a importância dos trabalhos e ideias de Cuvier, mas também para a compreensão da própria revolução darwiniana.

O fixismo de Cuvier e a pouca relevância que o conhecimento sobre o ambiente detinha em seus trabalhos estavam baseados em suas ideias sobre a organização interna dos seres vivos e os limites que tal organização impunha às modificações fisiológicas. Essa supremacia do pensamento fisiológico em detrimento do ecológico é representativa da época em o pensamento de Georges Cuvier era hegemônico, o pensamento de um fisiólogo de museu.

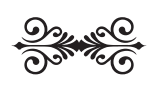

